\title{
Cerrahi için yüksek riskli bir hastada akut kolesistitin endoskopik transpapiller drenajı
}

\section{Endoscopic transpapillary drainage of acute cholecystitis in a high-risk patient for surgery}

\section{(D) Sinem IPOR ${ }^{1}$, (D) Mehmet Fuat ÇETIN ${ }^{2}$, (D) Attila ÖNMEZ ${ }^{1}$, (D) Alper Murat IPOR ${ }^{2}$, (D) Serkan TORUN ${ }^{3}$}

Düzce Üniversitesi Tıp Fakültesi, ${ }^{1}$ ç̧ Hastalıklan Anabilim Dall, ${ }^{2}$ Genel Cerrahi Anabilim Dalı, ${ }^{3}$ Gastroenteroloji Bilim Dalı, Düzce

Akut kolesistit, safra taşlarının sık görülen komplikasyonlarından birisidir. Akut kolesistit için genellikle kolesistektomi önerilir. En sık tercih edilen yöntem laparoskopik kolesistektomidir. Ancak ameliyatın kontrendike olduğu durumlarda endoskopik transpapiller safra kesesi drenajı alternatif bir yöntem olarak kabul edilir. 86 yaşında kadın hasta, acil servise, sağ üst kadran ağrısı ve ateş yüksekliği yakınmalarıla başvurduğunda çekilen abdomen tomografisinde taşh kolesistit saptandı. Hasta kolesistit, kolanjit ve biliyer sepsis ön tanılarıyla yatırılarak acil endoskopik retrograd kolanjiyografi yapildr. Safra kesesine $10 \mathrm{Fr} 10 \mathrm{~cm}$ double pigtail plastik stent ve sağ ve sol ana safra kanalına uzanacak şeklide iki adet 10 Fr double pigtail stent yerleştirildi. Işlem sonrası klinik takiplerinde hasta hızlıca düzeldi ve post-operatif 1 hafta sonra taburcu edildi. Safra kesesinin endoskopik drenajı, transpapiller yoldan veya transmural yoldan endoskopik ultrasonografi ile yapilabilir. Prosedür teknik olarak başarılı olduğunda, transpapiller drenaj, akut kolesistitli hastaların \%90'ından fazlasında etkili tedavi sağlar. Endoskopik drenaj yöntemleri kolesistektomi riski yüksek olan hastalarda teknik olarak uygulanabilir, güvenli ve etkili tekniklerdir.

Anahtar kelimeler: Kolesistit, kolanjit, endoskopik retrograd kolanjiyopankreatografi, endoskopik transpapiller safra kesesi drenajı
Acute cholecystitis is one of the common complications of gallstones. Cholecystectomy is generally recommended in patients with acute cholecystitis. The most preferred method is laparoscopic cholecystectomy. However, in cases where surgery is contraindicated, endoscopic transpapillary gallbladder drainage is considered an alternative method. An 86-year-old female patient was admitted to the emergency department with right upper quadrant pain and fever. An abdominal computed tomography scan revealed calculus cholecystitis. The patient was hospitalized with a prediagnosis of cholecystitis, cholangitis, and biliary sepsis, and urgent endoscopic retrograde cholangiopancreatography was performed. A 10-Fr 10-cm double-pigtail plastic stent was inserted into the gallbladder, and two 10-Fr double-pigtail stents extended into the right and left main bile ducts. In the clinical follow-up after the procedure, the patient recovered quickly and was discharged one week postoperatively. Endoscopic drainage of the gallbladder can be performed using endoscopic ultrasonography from either the transpapillary pathway or the transmural pathway. When the procedure is technically successful, transpapillary drainage provides effective treatment in more than $90 \%$ of patients with acute cholecystitis. Endoscopic drainage is a technically feasible, safe, and effective method used in patients at a high risk of cholecystectomy.

Key words: Cholecystitis, cholangitis, endoscopic retrograde cholangiopancreatography, endoscopic transpapillary gallbladder drainage

\section{GIIRISS}

Akut kolesistit safra taşlarının sık görülen komplikasyonlarından birisidir. Bildirilen akut kolesistit mortalitesi yaklaşı \%3 civarında olmakla birlikte bu oran hastanın yaşı veya komorbiditeleri ile artar (1). Kolesistit ataklarının tekrarlama riski yüksek olduğundan, akut kolesistit için genellikle kolesistektomi önerilir (2). En sık tercih edilen yöntem laparoskopik kolesistektomidir ancak yüksek cerrahi riskli hastalarda veya ameliyatın kontrendike olduğu durumlarda safra kesesinin drenajı alternatif olarak kabul edilir.

Perkütan transhepatik safra kesesi drenajı (PTSKD), safra kesesi drenajı için yaygın kullanılan bir yöntem (3) olmasına karşın bu yöntem ciddi koagülopati, trombositopeni riski olan veya anatomik olarak erişilemeyen safra kesesi olan hastalarda sınırlıdır. Iki endoskopik yöntem; endoskopik transpapiller safra kesesi drenajı (ETSD) ve endoskopik ultrasonografi eşliğinde transmural drenaj (EUS-SKD) cerrahi yapilamayan hastalarda PTSKD'ye alternatif olarak bildirilmiștir $(4,5)$. ETSD retrospektif çalışmalarda \%80.9'luk bir teknik başarı oranına sahiptir (5).

Ipor S, Çetin MF, Önmez A, et al. Endoscopic transpapillary drainage of acute cholecystitis in a high-risk patient for surgery. Endoscopy Gastrointestinal 2020;28:67-68.
Biz bu yazımızda yaşı ve komorbiditeleri nedeni ile opere edilemeyen ve tekrarlayan kolesistit atakları mevcut olması nedeni ile ETSD yapılan 86 yaşında kadın hastamızı sunmaktayız.

\section{OLGU SUNUMU}

Seksen altı yaşında kadın hasta, acil servise, sağ üst kadran ağrısı ve ateş yüksekliği yakınmalarıyla başvurduğunda çekilen abdomen tomografisinde taşlı kolesistit saptandı. Özgeçmişine bakıldığında hipertansiyon, tip 2 diabetes mellitus, koroner arter hastalı̆ı, konjestif kalp yetersizliği, kronik atriyal fibrilasyon tanıları ve bu nedenle antiagregan ve antikoagülan tedavi aldığı öğrenildi. Ayrıca son 6 ayda akut kolesistit tanılarıyla çeşitli sağlık merkezlerinde yatırılarak tedavi edildiği, fakat cerrahi için yüksek riskli olması nedeniyle kolesistektomi yapılmamış olduğu, en son 2 hafta önce başka bir merkezde yine akut kolesistit tanısıyla yatırıldığı ve antibiyoterapi ile taburcu edildiği öğrenildi. Hastanın acil serviste yapılan fizik muayenesinde; genel durumu kötü, bilinci uykuya meyilli, 


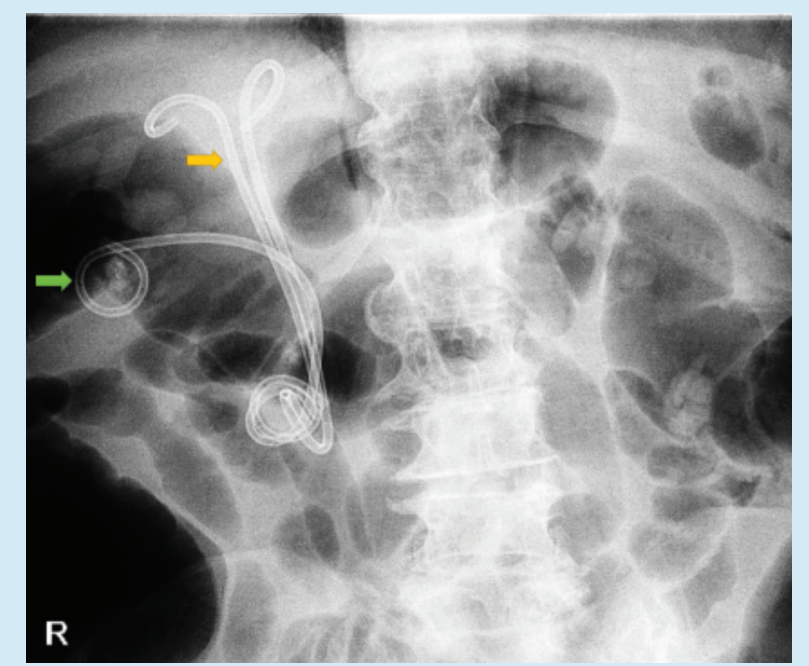

Resim 1. Safra kesesine yerleştirilen $10 \mathrm{Fr} 10 \mathrm{~cm}$ double pigtail plastik stent (yeşil ok) ve sağ ve sol ana safra kanalına uzanacak şeklide yerleştirilen iki adet $10 \mathrm{Fr}$ double pigtail stent (sarı ok).

hipotansif ve taşikardik idi. Laboratuvarına bakıldığında; beyaz küre: $20.510^{3} / \mathrm{uL}$, platelet: $9810^{3} / \mathrm{uL}$, C-reaktif protein: $21.8 \mathrm{mg} / \mathrm{dL}$, üre: $54.39 \mathrm{mg} / \mathrm{dL}$, kreatinin: $2.14 \mathrm{mg} / \mathrm{dL}$, alanin aminotrenasferaz: $310 \mathrm{U} / \mathrm{L}$, aspartat aminotransferaz: $380 \mathrm{U} / \mathrm{L}$, total bilirübin: $5.54 \mathrm{mg} / \mathrm{dL}$, direkt bilirübin: 3.46 $\mathrm{mg} / \mathrm{dL}$, alkalen fosfataz: $224.72 \mathrm{U} / \mathrm{L}$, gama-glutamil transpeptidaz: 237 U/L olarak görüldü. Hasta kolesistit, kolanjit ve biliyer sepsis ön tanılarıyla yatırılarak acil endoskopik retrograd kolanjiyografi (ERCP) yapıldı. Kolanjiyografide koledok geniş olmakla birlikte içerisinde taş izlenmedi, sfinkterotomi yapılarak safra yolları balonla kontrol edildi, temizdi. Ayrica tekrarlayan kolesistit atakları ve cerrahi için yüksek riskli ol-

\section{KAYNAKLAR}

1. Lee SO, Yim SK. Management of acute cholecystitis. Korean J Gastroenterol [Internet]. 2018;71:264-8.

2. Yokoe M, Hata J, Takada T, et al. Tokyo Guidelines 2018: diagnostic criteria and severity grading of acute cholecystitis (with videos). J Hepatobiliary Pancreat Sci 2018;25:41-54.

3. Peñas-Herrero I, De La Serna-Higuera C, Perez-Miranda M. Endoscopic ultrasound-guided gallbladder drainage for the management of acute cholecystitis (with video). J Hepatobiliary Pancreat Sci 2015;22:35-43. duğu gerekçesiyle kolesistektomi yapılamamış oluşu dikkate alınarak sistik kanal kılavuz telle bulunarak safra kesesine 10 Fr $10 \mathrm{~cm}$ double pigtail plastik stent yerleştirildi (Resim1), bu stentten püy geldiği dikkati çekti. Hastanın sepsis kliniği ve kolestaz enzmlerinin yüksekliği de dikkate alınarak sağ ve sol ana safra kanalına uzanacak şeklide iki adet 10 Fr double pigtail stent yerleştirildi. Isşlem sonrası klinik takiplerinde hasta hızlıca düzeldi ve post-operatif 1 hafta sonra taburcu edildi.

\section{TARTISQMA}

Kolesistit, safranın sistik kanaldan bozulmuş geçişine yanıt olarak ortaya çıkar. Vakaların \%90'ndan fazlası sistik kanalın veya safra kesesi boynunun safra taşları ile tıkanmasından kaynaklanır (5).

Safra kesesinin endoskopik drenajı, transpapiller yoldan veya transmural yoldan endoskopik ultrasonografi ile yapilabilir (6).

Prosedür teknik olarak başarılı olduğunda, transpapiller drenaj, akut kolesistitli hastaların \%90'ından fazlasında etkili tedavi sağlar (6). Safra kesesinin transpapiller drenajının kullanımı, genellikle uzun, dar ve kıvrımlı olan ve bir safra taşı ile tıkanmış olan kistik kanal boyunca kılavuz telin retrograd olarak ilerlemesinin teknik zorluğu ile sınılıdır. Endoskopik sfinkterotomi yapılmadığı takdirde de kanama riski düşüktür.

Endoskopik drenaj yöntemleri kolesistektomi riski yüksek olan hastalarda teknik olarak uygulanabilir, güvenli ve etkili tekniklerdir.

\section{"Tüm yazarlar herhangi bir çıkar çatışması olmadığını be- yan ederler."}

4. Itoi T, Coelho-Prabhu N, Baron TH. Endoscopic gallbladder drainage for management of acute cholecystitis. Gastrointest Endosc [Internet] 2010;71:1038-45

5. Widmer J, Alvarez P, Sharaiha RZ, et al. Endoscopic gallbladder drainage for acute cholecystitis. Clin Endosc 2015;48:411-20.

6. Baron TH, Grimm IS, Swanstrom LL. Interventional Approaches to Gallbladder Disease. Campion EW, editor. N Engl J Med [Internet]. 2015;373:357-65. 